\title{
INTRODUCCIÓN
}

\section{La primavera de las rebeliones populares árabes}

\author{
Gilberto Conde
}

Las rebeliones populares árabes de 2011 constituyen uno de esos raros acontecimientos que sacuden al mundo y de los que se seguirá hablando durante décadas. A menudo nos acostumbramos a situaciones cómodamente cotidianas olvidando que el cambio, lo impermanente, es lo único continuo. Los recientes movimientos árabes son una prueba de ello. Quizás se popularizó llamar "primavera árabe" a estos sucesos por lo refrescante y agradable que resultaba ver desde fuera lo que acontecía en una región en la que se pensaba que el tiempo se había congelado, en sociedades que se pensaban inmutables. Todos los autores aquí reunidos, especialistas en estudios del Medio Oriente, consideramos importante estudiar, entender estas rebeliones, y analizar qué es lo que cambia y lo que permanece. ¿Una región pulsante, activa, es una región cohesionada? Queremos averiguarlo; por ello este número especial de Regiones y Cohesión y mis siguientes reflexiones a manera de introducción.

\section{Las rebeliones árabes de 2011}

Grandes movilizaciones populares sacudieron a la mayoría de los países árabes durante $2011 .{ }^{1}$ La autoinmolación de un joven vendedor de frutas en un pueblo de Túnez, ante la arbitrariedad de la policía local, fue la chispa que encendió una pradera de descontento. Las causas de los estallidos, a la vez obvias y complejas, con sus grandes diferencias entre un país, una región, una comunidad, un grupo y otro, deben buscarse tanto en el hartazgo ante la corrupción, la falta de oportunidades económicas y, sobre todo, en la falta de libertades en Estados autoritarios establecidos en diferentes etapas durante la llamada Guerra Fría. ${ }^{2}$ Por todo lo anterior, las sociedades árabes muestran un resquebrajamiento también ligado a las contradicciones producto de la aplicación de políticas neoliberales y del proceso de globalización (a partir de la década de los ochenta). No 
obstante, hay que reconocer que las rebeliones también fueron habilitadas por algunas mejoras en el acceso a la educación y a tecnologías de la información y de la comunicación. La historia no pasa en vano. Los procesos de gran escala tienen efectos moleculares que contribuyen a transformar a las sociedades.

Para 2012, las rebeliones iniciadas el año anterior ya habían transformado a los países árabes y sus repercusiones se habían sentido más allá de sus fronteras (al menos en Estados Unidos, España e Israel). Cuatro presidentes árabes habían perdido su puesto (en Túnez, Egipto, Libia y Yemen $^{3}$ ) y parecía que uno más, el de Siria, iba a tener un destino similar. Otros gobiernos habían logrado mantenerse -otorgando concesiones o reprimiendo a los manifestantes- a pesar de que el descontento y las protestas continuaban. En Bahrein, por ejemplo, las protestas antigubernamentales continuaron durante 2012, pero recibieron menos atención de la prensa internacional que el proceso de Siria; en Jordania y en otros países siguió habiendo protestas, aunque no de la magnitud de las del año anterior. Hay que reconocer que a corto plazo la envergadura de los cambios ha sido menor de lo que premonizaba gran parte de la prensa dentro y fuera de la región. Sin embargo, los efectos a largo plazo prometen ser monumentales. Lo complejo de la situación se puede ver incluso en los países en los que las rebeliones han tenido logros importantes. Así, en Egipto, Mohammed Morsi, representante de los Hermanos Musulmanes, ${ }^{4}$ ilegales hasta 2011, llegó a ocupar la presidencia de la república en 2012. No obstante, en ese país los militares siguen detentando gran parte del poder. La sociedad egipcia está dividida en dos grandes bloques electorales de similar tamaño: mientras que en la segunda ronda de la elección presidencial de 2012 poco más del 51 \% de la población votó por los Hermanos Musulmanes, cerca del 49 \% prefirió votar por el heredero del poder anterior, temerosos del arrivo al poder de quienes optan por combinar política con religión.

Las movilizaciones prometían seguir afectando la configuración política y social de una región que no únicamente ha estado en el centro de la geopolítica mundial posterior a la Guerra Fría, sino que tiene una importancia clave para el futuro de la economía global con sus abundantes yacimientos de hidrocarburos y los difícilmente despreciables recursos financieros de sus élites.

\section{Falta de democracia y de libertad}

Desde que obtuvo su independencia, mediante un largo y diferenciado proceso durante el siglo $\mathrm{XX},{ }^{5}$ la región ha carecido de democracia, con re- 
lativas y pocas excepciones. Algunos autores, como Samuel P. Huntington (1998) y Bernard Lewis (1990), sugieren que el problema es el islam, la religión predominante en la zona, que, aseguran, está inherentemente ligado a un modo de gobierno religioso y que no puede regirse por la voluntad popular. Argumentos de este tipo han sido rebatidos desde diversos ángulos por numerosos autores, desde Edward Said (2001) hasta Asef Bayat (2007) o Esposito y Voll (1996). Durante siglos pasados, la democracia no existía en el Medio Oriente porque, al igual que Europa occidental, esta región vivía bajo regímenes monárquicos absolutistas, como el Imperio Otomano. Con la dominación europea y la colonización tampoco se estableció la democracia. Durante la descolonización después de la segunda guerra mundial (a finales de la década de los cuarenta y durante los años cincuenta), hubo elecciones, pero no se concretó la democracia.

$\mathrm{Ni}$ el clima internacional ni las inclinaciones de los líderes laicos o monárquicos de la época ayudaron en ese sentido. Por un lado, durante un par de décadas después de la segunda guerra mundial, el gobierno de Estados Unidos promovió golpes de Estado militares e incluso monárquicos contra gobiernos electos democráticamente, como el de Mohammed Mosadegh en Irán en 1952, y apoyó a las monarquías absolutas, como la de Arabia Saudí, estrecha aliada desde 1945. Por el otro, la Unión Soviética se caracterizaba por su régimen de partido único y gobierno basado en la autoridad de un líder. Los dirigentes laicos de la zona (tales como Gamal Abdel Naser en Egipto, Saddam Huseyn en Iraq y Hafez al-Asad en Siria) adoptaron este modelo, con lo que se terminó por cancelar la viabilidad de la democracia.

Las circunstancias de guerra permanente que caracterizaron al Medio Oriente desde la llamada Crisis de Suez en 1956, ${ }^{6}$ sirvieron para justificar el establecimiento del estado de excepción en diferentes países, con lo que se cancelaron los derechos fundamentales (inalienable rights) como los de libre expresión, asociación y manifestación. En algunos casos como en Egipto o Yemen del Sur se establecieron regímenes de partido único. En otros, el partido dominante toleró la existencia de otras formaciones partidarias, pero siempre supeditándolas a su guía. Tal fue el caso de Siria y de Iraq a partir de la década de los setenta.

Con la desaparición del llamado Bloque Comunista y el final de la Guerra Fría entre los años 1989 y 1991, se empezó a extender el derecho a la elección de gobiernos por votación popular en diferentes partes del mundo, pero no en la región árabe. América Latina y Sudáfrica son ejemplos característicos de este proceso. Sin embargo, el Medio Oriente y el Norte de África no se beneficiaron de esta tendencia. Por ejemplo, el resultado de las elecciones libres de 1991 en Argelia amenazaba con pasar el gobierno a un partido islamista. En respuesta, el ejército argelino realizó 
un golpe de Estado que fue bien visto por las potencias occidentales. Francia, la antigua potencia colonial que dominara Argelia desde 1830 hasta 1962, e incluso Estados Unidos cerraron los ojos ante los abusos de las autoridades argelinas.

La falta de libertades democráticas condujo a un ambiente insoportable para las poblaciones de la región. Tuve la oportunidad de conversar con habitantes de países árabes a finales de la década de los noventa e inicios de los años dos mil, y era común escuchar expresiones de resentimiento al respecto. ${ }^{7}$ Gracias a los altos precios alcanzados por el petróleo y los mecanismos de cooperación establecidos entre los países árabes exportadores del recurso y sus vecinos menos aventajados, la región vivió los años dorados de la economía mundial, más allá de los años cincuenta y sesenta.

Sin embargo, la situación se agravó con el deterioro posterior de las condiciones económicas. A partir de la década de los ochenta se implementó la ortodoxia capitalista con sus mecanismos de ajuste estructural en la región árabe. Como en el resto del mundo, los cambios llevaron a la privatización de empresas públicas, a priorizar los sectores que producían para la exportación y a la destrucción del Estado benefactor. El efecto, por supuesto, también fue la exclusión de amplios sectores de la población del mercado laboral.

Durante el periodo de expansión económica, particularmente en las décadas de los sesenta y setenta, en países como Egipto, Siria e Iraq, se había establecido una especie de pacto social o pacto de dominación ${ }^{8}$ por medio del cual la población cedía sus derechos fundamentales a cambio de un cierto grado de bienestar y porque se sentía representada en términos de la lucha nacional frente a Israel y las antiguas y nuevas potencias coloniales.

Durante la década de los setenta se dio una transición en el pacto social. El periodo nacionalista que siguió a la descolonización vio una serie de cambios de líderes radicales por otros "moderados", más dispuestos a establecer buenas relaciones con Estados Unidos y sus aliados en la región. A partir de los años ochenta, casi todos pasarían por la aplicación de medidas neoliberales en la economía, lo que llevó crecientemente al deterioro del pacto desde el punto de vista de la mayoría de la población.

Es importante subrayar que en la medida en que las condiciones sociales se agravaban y los dirigentes abandonaban la práctica nacionalista ${ }^{9}$, aunque conservaran el discurso, se siguieron manteniendo severos límites a los derechos fundamentales. ¿Cómo era esto posible? Las autoridades daban a entender que, de relajar el sistema, los enemigos de la patria (Israel, el imperialismo de Estados Unidos) o los grupos violentos del interior (fundamentalistas islámicos radicales) podían aprovechar para dividir a 
las sociedades árabes y hacerlas caer en una situación aún peor. Se trataba de una especie de chantaje con el que se amenazaba a la población con perder lo poco que quedaba del pacto de dominación.

\section{El petróleo, una paradoja}

En la región se encuentran los yacimientos más importantes de uno de los recursos más valorados en el mundo a inicios del siglo XXI: el petróleo. Esta condición natural culmina en una paradoja ya que el manejo de éstos recursos no necesariamente genera procesos de cohesión social en los países árabes; al contrario, el control de los hidrocarburos está ligado al dominio de sus sociedades y las de los países vecinos por diferentes medios, tanto económicos e ideológicos como represivos.

A finales de los años ochenta e inicios de los noventa, diversos autores (tales como Luciani, 1990, y Beblawi, 1990) adoptaron la idea de que la existencia de recursos como el petróleo daban una fuerza excepcional a los gobernantes árabes, ya que su estabilidad provenía de la renta de los hidrocarburos y no de los impuestos. Aunque los hidrocarburos siguen siendo una importante fuente de ingresos de las monarquías del Golfo y de sus élites en el siglo XXI, también existe un alto grado de diversificación de sus fuentes de ingreso. Muestra de ello son sus cuantiosas inversiones en el sector financiero, iniciadas desde la década de los setenta. Para el año 2011, por ejemplo, la corona qatarí realizó fuertes inversiones en Gran Bretaña, Francia, España y Grecia (Hamdan, 2011). Para octubre de ese año, se preparaba a invertir más de mil millones de dólares en la adquisición de dos bancos en Luxemburgo (Scott, 2011).

Las rebeliones de 2011 han puesto en duda la pertinencia del determinismo económico que denotan teorías como la de la renta petrolera. La complacencia o no de la población sigue siendo determinante para la estabilidad de un régimen. De ahí que la monarquía saudí haya asignado decenas de miles de millones de dólares a programas sociales durante el año para evitar que las movilizaciones en su país se convirtieran en levantamientos similares a los de sus vecinos (Hertog, 2011; MacFarquhar, 2011). Para garantizar el éxito de estas medidas, sin embargo, la monarquía decidió combinarlas con represión (Abou Al-Samh, 2011).

Los gobiernos agrupados en el Consejo de Cooperación del Golfo $(\mathrm{CCG}){ }_{1}^{10}$ han hecho frente a los movimientos políticos que se originan en sus propios países; sin embargo, también han desplegado esfuerzos por influir en los procesos políticos de otros países árabes e islámicos. En el caso de Arabia Saudí el proceso ya tiene varias décadas (por ejemplo mediante sus esfuerzos en Afganistán desde 1979). Cuando los movimientos demo- 
cráticos de la primavera árabe se empezaron a extender de un país a otro, uno de esos países, Arabia Saudí, empezó a buscar formas de mantener el statu quo ante. La tendencia se agudizó cuando se empezaron a contagiar algunos países miembros del Consejo, como Bahrein, Omán, Kuwait y la propia Arabia Saudí. Varios de los miembros del CCG están plenamente involucrados en los acontecimientos regionales. Arabia Saudí y los Emiratos Árabes Unidos enviaron tropas en apoyo al regímen Bahreiní. En Yemen, el Consejo intentó fungir como mediador entre el gobierno de Ali Abdallah Saleh y la oposición desde 2011, hasta que en febrero de 2012 obligó al presidente a renunciar antes de que se agudizara más la crisis. Es necesario mencionar que amplios sectores de la oposición yemení dudan de la imparcialidad del CCG. En los países en que los miembros del Consejo han dado por hecho que el cambio es inevitable -como en Túnez o Egipto- o incluso deseable para sus intereses -como en Libia o Siria- han apoyando a los grupos de oposición (AbuKhalil, 2012; Ibrahim, 2011).

No se trata realmente de una práctica nueva. Tras la derrota de los nacionalistas árabes en la guerra de junio de 1967 ante Israel, los líderes de las monarquías más ricas en petróleo ofrecieron recursos a las repúblicas árabes (Corm, 1999) y multiplicaron las sumas dedicadas a la cooperación para el desarrollo en los países vecinos. Después de la Cumbre de Jartum, ${ }^{11}$ se operaron cambios en los liderazgos políticos de la región y se establecieron los llamados gobiernos "moderados". A partir de entonces, el laicismo perdió fuerza mientras se expandieron los movimientos islamistas.

Todo este escenario resalta el poder económico de las petromonarquías en asimetría con las sociedades de la región, sus luchas por definir su futuro y conquistar sus libertades. En marzo de 2011, un autor occidental explicaba en un blog de The New York Times (Mulligan, 2011) que Libia, como cualquier país rico en petróleo, difícilmente conocerá la democracia. Sin embargo, no es el petróleo en sí el que tiene la última palabra. Se trata como siempre de una lucha entre fuerzas en que los explotadores de los recursos harán todo por mantener sus privilegios y el resto de la población buscará mejorar sus condiciones tanto materiales como de derechos fundamentales.

\section{Desafíos geopolíticos: las dos revoluciones árabes}

Desde inicios del siglo XX, la abundancia petrolera ha dado aliento a diversas ambiciones de dominación foránea sobre la región (Kolko, 2006). En la medida en la que la producción capitalista mundial se ha ido tornando más dependiente del recurso energético y en la que la competencia 
entre viejos y nuevos grupos se agudiza, el control de las fuentes de hidrocarburos adquiere una importancia crucial. Para nadie es desconocido que el Medio Oriente y el Norte de África albergan algunas de las mayores reservas petroleras del mundo. La región, además, se encuentra en un punto clave de Eurasia, ${ }^{12}$ en medio de rutas de comunicaciones y transportes internacionales de primera importancia.

Los movimientos populares de 2011 pusieron en duda un orden que, a pesar de avatares notorios, se había establecido paulatinamente, y con dificultades, entre 1967 y 1978. Dicho orden garantizaba los flujos de petróleo y un frágil pero importante grado de estabilidad que permitía la realización de importantes objetivos de los gobiernos y las élites estadounidenses y europeas en la región. Los primeros gobernantes en caer, en enero y febrero de 2011, eran viejos y seguros aliados de las potencias occidentales $y$, aunque en las movilizaciones no se mencionaba a Occidente ni a sus aliados en la región, tampoco quedaba claro que los sectores ascendentes fueran fáciles de controlar. Finalmente, eran fuerzas de izquierda las que tenían la iniciativa. Detrás de los temas democráticos y sociales, era todo un orden geopolítico el que estaba en juego.

Sin embargo, mientras que el momento planteaba desafíos, también ofrecía oportunidades. La administración estadounidense se propuso tomar en positivo las movilizaciones para apoyar movimientos democráticos en el Medio Oriente de manera que le permitiera mejorar opiniones sobre los Estados Unidos en la región. Así lo dio a entender el presidente Barak Obama (2011) en su discurso el 19 de mayo de 2011.

En su alocución, planteó claramente que su gobierno apoyaría movimientos de los países en los que ya se había derrocado a los presidentes, como Túnez y Egipto, y de algunos más pero no todos: "we cannot prevent every injustice perpetrated by a regime against its people (no podemos prevenir cada injusticia perpetrada por un régimen contra su pueblo)". Y mencionó los criterios en que se basaría para intervenir en un sitio y no en otro: el peligro de represión, el costo de la intervención, así como los intereses centrales de Estados Unidos. Más aún, mencionó las prioridades: Libia y Siria. Yemen y Bahrein recibirían otro trato. En el primero, se organizaría una transferencia ordenada del mando y en el segundo se promovería un diálogo entre el gobierno y la oposición. En mi opinión, el discurso dejaba claro que en ninguno de estos dos, sin embargo, habrían de ocurrir cambios de fondo.

Mientras tanto, aunque en el citado discurso Obama indicó que alentaría a los países a realizar reformas, en la realidad la administración mantuvo una postura doble ante los movimientos populares en el mundo árabe. Parecía decir que había revoluciones que merecían ser apoyadas y otras que habría que desalentar o al menos tener bajo control. El apoyo en 
Yemen se preveía en términos de una transición controlada; en Bahrein, en términos de limitar la represión. Después de todo, Yemen era pieza clave

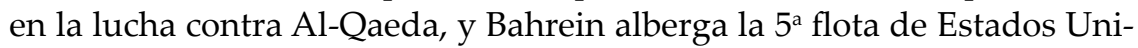
dos. Por otro lado, para Egipto y Túnez se proponían apoyos económicos. Aquellas revueltas que se oponían a líderes incómodos desde el punto de vista de la administración estadounidense, las de Libia y Siria, se hicieron merecedoras de apoyo.

Curiosamente, se trata de una actitud similar, sólo que que a la inversa (como si se viera en un espejo -donde la izquierda se ve en la derecha y viceversa-), a la adoptada por el presidente de Venezuela ante los mismos conflictos. Para Hugo Chávez, los movimientos rebeldes árabes son vistos con buenos ojos, salvo cuando cuestionan a líderes que él identifica con el anti-imperialismo (como Irán, Libia o Siria). La gran diferencia, sin embargo, es el limitado poder de Chávez, a diferencia de Obama, de incidir en los acontecimientos.

\section{La primavera del 99 por ciento}

¿Por qué han sido tan revolucionarios estos movimientos? Probablemente porque manifestaron el hartazgo de millones con dos fenómenos que, finalmente, no sólo los han afectado a ellos durante décadas, sino que tienen mucho que ver con la situación del resto del mundo: el deterioro en las condiciones de vida en el contexto de la globalización, a pesar de un acceso creciente a medios culturales y de comunicación, y la imposibilidad que padece la gran mayoría de la población para influir en las grandes decisiones que los afectan en sus vidas diarias.

La simpatía generalizada que se observó en el mundo hacia los movimientos que recibieron el nombre de "primavera árabe" reflejaba algo más profundo, una verdadera empatía por una lucha contra la injusticia social. Por ello el contagio desbordó rápidamente las fronteras del mundo árabe, suscitando movilizaciones masivas de protesta en diversos países fuera de la región.

El diagnóstico del problema contra el que se rebelan los manifestantes en todos lados pasa rápidamente de las afecciones económicas o discriminatorias a un problema más fundamental de relaciones de poder. Lo que está en tela de juicio, finalmente, es quién toma las decisiones. En los países árabes las rebeliones se oponen a la dictadura exigiendo democracia, en otros cuestionan el modelo democrático en vigor y demandan "democracia verdadera". Estas movilizaciones, insisto, parecen interrogarse sobre el significado profundo de la soberanía popular y de los modelos de democracia dominantes, como si preguntaran: ¿debe tomar las decisiones 
el uno por ciento que detenta la práctica del poder o el 99 por ciento restante que sufre sus consecuencias? ¿La democracia consiste en depositar una papeleta en una urna cada cierto número de años? ¿O es el proceso mismo de toma de decisiones y no sólo de elección de representantes el que debería ser democrático?

Durante las movilizaciones de la primavera y el verano de 2011, a los españoles no sólo les indignaba la falta de oportunidades económicas, sino el propio modelo de democracia en vigor. Al demandar "democracia real ya", expresaban su malestar con las condiciones económicas a las que el capitalismo del siglo XXI los somete, relacionando la profundidad de sus orígenes con el hartazgo de los árabes en Túnez y en la Plaza de la Liberación en Cairo (Cf. Democracia Real Ya!, 2011). Es decir, el problema no era únicamente el desempleo, los salarios bajos y el alto costo de los bienes y servicios, sino quién toma las decisiones del rumbo que debe seguir la sociedad. Este problema no es exclusivo de los árabes, ya que afecta prácticamente a todo el orbe. No obstante, no hay que olvidar que los pueblos árabes han visto burlados numerosos derechos básicos: libertad de expresión, reunión, manifestación, participación en la selección de sus gobernantes y de incidir en la toma de grandes y hasta de pequeñas decisiones.

Efectivamente, es necesario preguntarnos ¿quién posee el modelo de democracia a aplicar en los países árabes y en el resto del mundo? ¿Estados Unidos, Venezuela, Irán? ¿Qué hace más válido a uno sobre los demás? David Held (2006) ha explicado reiteradamente que existen diversos modelos, desde la polis ateniense, con su democracia directa, hasta las democracias representativas.

De hecho, ese era el principal cuestionamiento que formulaban las oposiciones de izquierda a los regímenes del llamado socialismo real antes de la caída del Bloque Soviético entre 1989 y 1991. Poco después de la implosión de estos regímenes, el levantamiento zapatista de los indígenas de Chiapas en México, en 1994, renovó ese mismo planteamiento. Con su famosa frase de "mandar obedeciendo", expusieron que lo importante no es tanto quién gobierna, sino quién toma las decisiones y cuál debe ser, finalmente, la función del gobernante.

La conclusión a la que llegaron los zapatistas, en parte gracias a las tradiciones comunitarias de los pueblos indígenas, es muy similar a la que llegaron los movimientos aparecidos en 2011. Los manifestantes de Occupy Wall Street pusieron en cuestión la legitimidad del régimen imperante en las democracias occidentales al afirmar que el uno por ciento toma todas las decisiones y el 99 por ciento está prácticamente excluido. ${ }^{13}$

En Grecia, esta situación quedó claramente ilustrada en el otoño de 2011. En medio de la crisis económica y las protestas masivas, el entonces 
primer ministro George Papandreou anunció su intención de convocar a un referéndum en el que la población pudiera aprobar las condiciones que exigían las autoridades de la zona del Euro para otorgar una serie de préstamos al país. Rápidamente se registraron grandes fugas de capitales que exacerbaron la crisis de liquidez y llevaron a la renuncia de Papandreou así como a la formación de un nuevo gobierno sujeto a las presiones del capital financiero (Smith, 2011).

\section{¿Qué opciones se plantean los movimientos de protesta?}

Para imaginar futuros posibles en los países árabes, es necesario entender qué opciones se plantean los movimientos de protesta. En ocasiones, las reivindicaciones parecen vagas o ambiguas, sobre todo porque algunos de los sectores movilizados escapan a la lógica de partidos políticos. ${ }^{14} \mathrm{No}$ obstante, entre las fuerzas organizadas presentes se cuentan las islamistas, nacionalistas, liberales y socialistas o incluso comunistas. Es importante conocer los marcos en los que se ubican las movilizaciones y las diversas fuerzas presentes para entender qué tipo de opciones se van conformando para los países de la región. Quedan por responder numerosas preguntas importantes sobre estas movilizaciones y el futuro de los países árabes: ¿qué institucionalidad se propone? ¿Cuál es el lugar de las mujeres en las movilizaciones y qué dicen sobre su futuro? ¿Qué le espera al pluralismo religioso y al pluralismo étnico?

Las protestas de Túnez y Egipto se explican en parte por el hartazgo generalizado de la población con las circunstancias mencionadas al inicio de esta introducción. La veloz extensión de las movilizaciones al resto de los países árabes evidencia que el descontento era cosa común en otros países también.

¿Por qué otras movilizaciones no tuvieron el mismo éxito que en Egipto y Túnez? La explicación es múltiple. Una de las razones para el éxito fulminante de los movimientos populares en Túnez y Egipto fue que se creó de manera espontánea y rápida una hegemonía muy amplia a favor del establecimiento de la democracia, en sentido abstracto, en lugar de los regímenes dictatoriales. ${ }^{15} \mathrm{Ni}$ los gobiernos en cuestión, ni las ricas monarquías del Golfo, ni las jerarquías internacionales, Estados Unidos y la Unión Europea, tuvieron tiempo para reaccionar ante los acontecimientos. Fracasaron los intentos de Ben Ali y de Mubarak por dividir a la población o asustarla con la vieja amenaza del islamismo. Mientras que musulmanes y coptos, islamistas y laicos, socialistas, liberales y conservadores coincidían en Plaza Tahrir, los oficiales del ejército percibían que las tropas se resistirían a reprimir a una población que expresaba lo que 
los mismos soldados sentían. Los movimientos en otros países tuvieron evoluciones diferentes. Algunos, en Marruecos o Jordania, lograron ser mediatizados con concesiones especiales. Por ejemplo, la monarquía jordana cambió rápidamente al gobierno, mientras que la marroquí introdujo una reforma constitucional y permitió la llegada de los fundamentalistas al gobierno. Otros fueron aplastados por la represión, como en Bahrein. Otros más continuaron en condiciones difíciles. La victoria de la oposición libia requirió de un esfuerzo mucho mayor al de los egipcios. En Yemen, a pesar de la represión y de ciertos logros, como la salida nominal del presidente Ali Abdallah Saleh, las manifestaciones continuaron, pero con severas dificultades para lograr un verdadero cambio de régimen. La situación en Siria no era mucho mejor, con severa represión gubernamental y una creciente lucha armada de los rebeldes que, sin embargo, no lograba cambios profundos.

Uno de los fenómenos con fuertes repercusiones sobre el curso de los acontecimientos fue la ya mencionada bifurcación de los escenarios entre las revoluciones que recibieron apoyo del exterior y las que no, en el contexto de la geopolítica de las grandes potencias. La guerra de Libia, con la intervención de la Organización del Tratado del Atlántico Norte (OTAN) y de fuerzas qataríes en apoyo a los rebeldes, tuvo un efecto contradictorio sobre las mentes de los pueblos de la región. En Yemen o Bahrein, los manifestantes apoyaban a sus pares libios pero identificaban la dualidad de los poderosos, árabes u occidentales, conscientes de que no vendrían a auxiliarlos contra sus dictadores. En Siria, en cambio, los acontecimientos de Libia indicaban que se podía esperar que las fuerzas extranjeras, occidentales y las monarquías del Golfo Pérsico, respaldaran la rebelión contra el régimen del partido Baaz.

Mientras para algunos sectores de la oposición siria, en un inicio minoritarios, el ejemplo libio trazaba su propio camino para deshacerse del gobierno del partido Baaz, para otros grupos de la oposición y, sobre todo, para amplios sectores de la población, el escenario de intervención externa era ominoso. La idea de ver Damasco o Alepo sumergidos bajo las bombas parecía poco atractivo. ${ }^{16}$

Así, tras las primeras movilizaciones, se ha visto una mayor fragmentación de las diversas fuerzas sociales ante el tema de la caída de los regímenes. Algunos comerciantes, ciertas minorías -y en ocasiones mayorías- étnicas y religiosas buscan la caída de los regímenes, pero otros ven a sus gobernantes como un mal menor. Este es uno de los motivos que permitió al sistema sirio mantener un respaldo popular indiscutible, por ejemplo.

No obstante, en dos de los países en los que para mediados de 2012 se había logrado deponer a los principales líderes del pasado, Zine el- 
Abidine Ben Ali en Túnez y Hosni Mubarak en Egipto, eran los partidos islamistas los que lograban atraer a la mayoría de la población a la hora de las elecciones. Al inicio de las movilizaciones, las reivindicaciones consistían, muy sencillamente, en demandar la defenestración de los dictadores, el final de los regímenes autoritarios y la desaparición de la corrupción. Los temas típicos de los islamistas, tales como el establecimiento de la shari' $a^{17}$ como ley fundamental, no estaban presentes. Puedo interpretar que sus temas no constituían la preocupación principal de los manifestantes.

Al menos dos causas explican esta evolución. Por un lado, durante décadas, la mezquita ha sido un lugar privilegiado en el que sectores importantes de la población han podido expresar su descontento, así haya sido en voz baja. Por el otro, los conservadores grupos islamistas se han ganado una reputación de opositores a los regímenes tanto laicos como religiosos. Además, los fundamentalistas islámicos han recibido importante apoyo financiero de los países del Golfo por medio de organizaciones de beneficencia y de trabajadores que han migrado a esos mismos países y han sido influidos por el islamismo en el poder en ellos.

Mientras tanto, tras una época de alta credibilidad durante los años sesenta y setenta, los grupos laicos de oposición perdieron gran parte de su atractivo, tanto por la derrota de los gobiernos identificados como de izquierda ante Israel en la guerra de 1967, como por otras derrotas identificadas con la izquierda, incluso a escala internacional con la desaparición del llamado socialismo real a finales de los ochenta. También pesaron los grandes recursos asignados por las monarquías petroleras del Golfo en todo el mundo árabe e islámico durante décadas (Corm, 1999), aunque, hay que aclarar, la mayor parte de la ayuda para el desarrollo que otorgaron estos países no estuvo condicionada (Van de Boogaerde, 1991).

Queda entonces pendiente la pregunta de qué futuro le espera a estos países durante los años por venir. Parece tener razón Achcar (2012) cuando dice que el ascenso del islamismo al poder en los países que logren tumbar a sus regímenes, es inevitable, pero que las fuerzas progresistas que aparecieron durante 2011 podrían tomar la iniciativa en el futuro a condición de que logren organizarse de manera independiente.

Indudablemente, las rebeliones populares ocurridas en los países árabes durante 2011 y que con diferentes intensidades continuaban durante 2012 han tenido un efecto monumental sobre las consciencias de su población. Derrocar a los presidentes de Túnez y Egipto de manera pacífica con la simple movilización popular, lograr la ayuda externa para poner fin al régimen en Libia, y forzar a la comunidad internacional para la remoción del presidente de Yemen son hazañas que parecían literalmente imposibles a finales de 2010. Por supuesto, las fuerzas conservadoras son 
muy importantes y cuentan con muchos recursos. Me parece obvio que éstas harán todo lo posible por conducir a los países árabes por vías que garanticen sus intereses. No obstante, como se ha visto con acontecimientos similares en otras partes del mundo, es inevitable que estas revueltas tengan grandes efectos a largo plazo.

\section{Reflexiones sobre las revueltas árabes en Regiones y Cohesión}

Las ciencias políticas y sociales tienen un gran desafío de comprender lo que ha sucedido en los países árabes en los años 2011 y 2012 y lo que queda por ocurrir. Como se puede intuir de la lectura de las páginas anteriores, las preguntas que surgen son tan numerosas como las ideas de lo que creímos establecido en el mundo árabe y lo cual debemos ahora repensar. El número de Regiones y Cohesión que ponemos en sus manos es el producto de un esfuerzo de reflexión y replanteamiento de preguntas $\mathrm{y}$ respuestas.

En el otoño de 2011 me acerqué a mis colegas Carmen Maganda y Harlan Koff, editores de la revista, para proponerles la preparación de este número especial, convencido que Regiones y Cohesión era el lugar ideal para realizar este ejercicio. Se trataba de reunir estudios y reflexiones acerca de la serie de acontecimientos más importantes ocurridos en una región en la que todo lo que sucede tiene siempre repercusiones en el resto del mundo. Además, si hay algo que estas rebeliones ponen en cuestión es la paradójica falta de mecanismos eficientes de cohesión social en una región rica en recursos energéticos sumamente valiosos. Los editores de Regiones y Cohesión tomaron con entusiasmo la propuesta, y enfrentamos el reto de reunir a un cierto número de expertos.

Generalmente, los que más escriben acerca del mundo árabe son autores europeos o estadounidenses. Siendo ésta una revista que analiza lo regional y que se distribuye en diversas áreas del mundo, me pareció importante reunir especialistas de otras regiones donde no es común, o es muy escaso, encontrar escritos sobre estos temas, pero cuyos autores tienen mucho que decir dada su propia historia de dictaduras y rebeliones. Así, decidí reunir especialistas provenientes principalmente del mundo iberoamericano.

Colaboraron en este número la historiadora Camila Pastor de María y Campos, del Centro de Investigaciones y Desarrollo Económicos de México, Isaías Barreñada, destacado investigador que trabajó durante años en la Casa Árabe de Madrid, Víctor de Currea-Lugo, profesor e investigador de la Universidad Javeriana de Bogotá y periodista, Pedro Buendía, investigador del área de estudios árabes e islámicos de la Universidad de 
Salamanca, María de Lourdes Sierra Kobeh, experta en temas del Medio Oriente que ha contribuido a formar generaciones enteras de especialistas en la Universidad Nacional Autónoma de México. También colaboraron en el foro de liderazgo, Michael Provence, reconocido profesor de historia árabe de la Universidad de California en San Diego, y Pentti Väänänen, dirigente de la Internacional Socialista y encargado de asuntos internacionales de su sección finlandesa. Para dar cobertura al importante perfil multilingue de Regiones y Cohesión, cinco de los éstos artículos están escritos en inglés y tres en español.

Este número especial titulado ¿Una nueva época? Las rebeliones de la primavera árabe y los levantamientos anteriores, se caracteriza por una amplia versatilidad que permitirá al lector entender que los movimientos populares árabes no aparecieron ex nihilo, sino que surgieron de una tradición de lucha y cierto grado de organización social a pesar del autoritarismo preexistente y que han adquirido vida propia con un alto grado de creatividad e ingenio popular a pesar de los fuertes y graves desafíos que penden sobre ellos. Así, seis de los artículos se basan en trabajos de investigación académica acerca de los levantamientos populares árabes, algunos de los cuales se enfocan particularmente en los eventos de 2011, sus antecedentes históricos, las visiones externas, sus debates políticos y sus medios de expresión. También se presenta un par de artículos históriconormativos escritos por dos autores que vivieron acontecimientos importantes relacionados con el Medio Oriente en diferentes periodos y que sirven para entender algunos antecedentes históricos de las revueltas populares de las que trata este número de la revista.

Camila Pastor, en "Revolt and revolution in the modern Middle East: 1830-2012", nos recuerda que las rebeliones populares no son eventos nuevos en los países árabes. Al contrario, han ocurrido de manera recurrente durante los últimos dos siglos. La autora aprovecha el ejercicio para analizar el paisaje social y la dinámica de las movilizaciones actuales.

En "El continuum contestatario en los países árabes: movimientos sociales, sociedad civil y ciudadanía" econtramos información que no se suele poner en relieve cuando se tratan los recientes movimientos sociales árabes. En este texto, Isaías Barreñada muestra que las movilizaciones de las llamadas "primaveras árabes" encuentran sus raíces en movimientos sindicales y juveniles contestatarios que habían estado sucediendo de manera creciente durante los últimos años.

Víctor de Currea-Lugo se rebela con justa razón contra las visiones de las rebeliones árabes que buscan su causa en un factor único, generalmente predeterminado por las inclinaciones ideológicas de quienes así las quieren comprender. Su artículo, "Questioning 'mono-causal' perceptions of the Arab revolts", revisa de manera crítica estas visiones unidimensionales. 
Como en todo movimiento revolucionario y a falta de acceso a los medios masivos de comunicación más allá del internet, los egipcios transformaron los muros urbanos en vehículo de expresión de su revuelta. Pedro Buendía nos ofrece una refrescante lectura: "Arte urbano, espacio público y subversión política: la revolución egipcia a través del graffiti", ilustrado con fotografías, en el que analiza las implicaciones de este fenómeno de relevancia contemporánea.

En "Framed between change and stability: Syria between people's revolution and regime survival", yo, Gilberto Conde, analizo las formas en las que el régimen y los movimientos de la llamada "revolución siria" combatieron en el terreno ideológico durante el primer año de protestas con el fin de entender el factor ideológico en el estancamiento del proceso de cambio en ese país hacia finales de 2011.

Después del primer año de movilizaciones se hacía imperativo realizar un primer balance de las movilizaciones. María de Lourdes Sierra Kobeh nos hizo el favor de asumir la tarea, buscando e identificando los desafíos que enfrentan los movimientos a pesar de haber obtenido algunos logros, como la caída de ciertos dictadores. En su artículo, "El mundo árabe a un año de las revueltas populares", la autora incluye un interesante análisis de los retos que representa la interferencia de las potencias extranjeras en los conflictos de esta región.

En el Foro de Liderazgo de Regiones y Cohesión, Michael Provence nos presenta una panorámica del régimen de Bashar Al-Asad, sobre el que hay pocos estudios académicos. "Unraveling the Syrian revolution" es un texto atractivo y ameno donde Provence nos comparte su experiencia personal y como historiador, una interesante búsqueda por comprender los orígenes de la protesta popular en 2012 y la respuesta ampliamente militar del régimen.

En esa misma sección, es un orgullo para mí presentar el interesante análisis de Pentti Väänänen: "Fostering peace through dialogue: The international social democratic movement and the Israeli-Palestinian conflict" en el cuál nos permite conocer de primera mano su relevante experiencia como dirigente de la Internacional Socialista, y nos explica cómo evolucionó la visión y acción de ese movimiento político ante el conflicto israelí-palestino.

Estoy convencido de que los lectores de diferentes partes del mundo encontrarán, en esta compilación de textos, importantes elementos de análisis y visiones diferentes a las que puedan leer en otros sitios. Agradezco a cada uno de los autores por su entusiasta, puntual y profesional colaboración con este número. Después de un año de preparación y trabajo editorial, el resultado nos satisface a todos, a mi personalmente, y por ello les invito a leer y disfrutar de este número especial de Regiones y Cohesión. 


\section{NOTAS}

1. El apelativo de "primavera árabe" fue acuñado por la prensa internacional. Numerosos académicos han optado por no dar un nombre especial a los movimientos de protesta árabes de 2011-2012 y prefieren describirlos.

2. Durante la Guerra Fría (1947-1991), el mundo se dividió en dos grandes bloques que se veían como rivales: el Bloque Occidental bajo la hegemonía de Estados Unidos, el Bloque Comunista bajo el liderazgo de la ahora extinta Unión Soviética. Se le llamó guerra fría porque durante esos años los dos países más prominentes de cada bando se enfrentaban, pero no en una guerra abierta.

3. Es importante aclarar que aunque el presidente de Yemen, Ali Abdallah Saleh, había formalmente abandonado su puesto, en realidad seguía detentando el poder real detrás del gobierno formal todavía a finales de 2012.

4. La Sociedad de los Hermanos Musulmanes es una organización fundamentalista islámica establecida originalmente en Egipto en 1928 y que se ha extendido en el resto de los países árabes con la consigna central de "el islam es la solución". Prohibida en algunos lugares y tolerada en otros, se ha convertido en vehículo del descontento social en muchos de esos países.

5. La historia de la independencia de los países árabes es compleja. Tras la Primera Guerra Mundial, los que aún formaban parte del Imperio Otomano se constituyeron en Estados, pero quedaron bajo la dominación de Gran Bretaña o Francia por mandato de la Liga de las Naciones. De estos, Iraq obtuvo su independencia formal en 1933. Terminada la Segunda Guerra Mundial, las potencias mandatarias otorgaron la independencia a Jordania, Líbano y Siria. De los que habían quedado por fuera del Imperio Otomano desde antes, Egipto se independizó, al menos en términos formales desde 1922. El resto de los países del norte de África conquistaron la independencia de Francia y de Gran Bretaña entre las décadas de los cincuenta y sesenta. En los países árabes del Golfo, Arabia Saudita y Omán no pasaron por un proceso de colonización como el resto de los países árabes. A los demás países del Golfo, Gran Bretaña les otorgó la independencia a inicios de los años setenta.

6. En 1956, el presidente egipcio Gamal Abdel Naser nacionalizó el canal de Suez, que había sido construido un siglo atrás por intereses británicos y franceses, con el objetivo de obtener los recursos financieros necesarios para la construcción de la gran presa de Aswán sobre el río Nilo. En respuesta, las fuerzas armadas de Gran Bretaña, Francia e Israel atacaron a Egipto desatando una crisis que amenazó la estabilidad mundial ante la fuerte reacción de la Unión Soviética. El presidente Dwight D. Eisenhower de Estados Unidos intervino para detener a sus aliados y distender la crisis.

7. Mientras cursaba la maestría y el doctorado en estudios de Medio Oriente y Norte de África en El Colegio de México entre 1997 y 2003, pude realizar varios viajes y estancias de investigación en países árabes, tales como Egipto, Siria, Líbano y Marruecos.

8. Viviane Brachet-Márquez (1996) lo denomina pacto de dominación, porque la población ofrece su pasividad a cambio de ciertas condiciones de vida relativamente favorables (véase también Arteaga Pérez and Brachet-Márquez, 2011). 
9. El nacionalismo se manifestó en la práctica en la resistencia de ciertos gobiernos árabes a las políticas de las potencias. Fue el caso de Egipto con la ya mencionada nacionalización del canal de Suez en 1956 cuando el Banco Internacional de Reconstrucción y Fomento se negó a otorgar créditos para la construcción de la presa de Aswán, o el de Egipto, Siria e Iraq al apoyar a la resistencia palestina. La última gran hazaña de los gobiernos nacionalistas fue cuando Egipto y Siria se pusieron de acuerdo para lanzar una acción conjunta contra Israel en octubre de 1973 con el objetivo de recuperar parte de los territorios que este país les arrebató en la guerra de junio de 1967. Después, Egipto firmó la paz con Israel en 1978, Siria intervino en Líbano para desmovilizar a la guerrilla nacionalista y a los grupos palestinos, Iraq entró en guerra con Irán en parte para congraciarse con las monarquías del Golfo Pérsico. El nacionalismo de los gobiernos laicos se había convertido en un nacionalismo esencialmente de discurso.

10. El Consejo de Cooperación del Golfo, fundado en 1981, incluye a las monarquías de la península arábiga: Arabia Saudí, Bahrein, Emiratos Árabes Unidos, Kuwait, Omán y Qatar.

11. Poco después de la victoria israelí sobre sus vecinos árabes en la guerra de junio de 1967, el 29 de agosto del mismo año, tuvo lugar en Jartum, capital de Sudán, la cuarta cumbre de jefes de Estado de la Liga Árabe en la que se tomó una postura unificada ante el conflicto israelí-árabe. En la cumbre, los países petroleros se comprometieron a dar un apoyo financiero a los países árabes que se habían visto involucrados en el conflicto bélico.

12. Eurasia es una enorme masa terrestre que incluye Europa y Asia, ocupa más de $32 \%$ de la superficie continental de la tierra y la habita más de $72 \%$ de la población mundial.

13. Por ejemplo, en el sitio: http://www.adbusters.org/campaigns/occupywalls treet promovido por Occupy Wall Street (2012), se reivindica la falta voluntaria de líderes, la inspiración en los levantamientos árabes y las movilizaciones españolas, y el objetivo de acabar con la corrupción de la democracia por el poder del dinero.

14. En Egipto, Túnez, Libia y Siria, los partidos políticos tuvieron una influencia marginal en los movimientos de 2011. En fases posteriores, una vez que se organizaron elecciones, los partidos islamistas de Egipto y Túnez lograron capitalizar los efectos de la movilización. En Bahrein y en Yemen, sin embargo, sí hubo partidos de oposición que se pusieron a la cabeza de las movilizaciones. Aún en estos dos países, sin embargo, hubo sectores importantes que participaron en las manifestaciones sin pertenecer ni simpatizar con los partidos.

15. La televisión por satélite y el uso de otras tecnologías de la información y la comunicación, como las redes sociales, también desempeñaron un papel importante en la velocidad en la que se desenvolvieron los acontecimientos.

16. Véase en mi artículo sobre Siria en este mismo volumen, la evolución del debate ideológico dentro de la oposición al respecto.

17. La shari'a es la ley islámica codificada durante los primeros siglos del islam. Aunque entre los sunníes existen cuatro escuelas de jurisprudencia, algunas más rigurosas que otras, las cuatro se basan en los preceptos del Corán, la 
tradición de dichos y hechos del profeta Muhammad, la analogía jurídica para casos no previstos y el consenso entre los doctores de la fe. Uno de los puntos en que coinciden diversos ideólogos del fundamentalismo islámico es la importancia de que las sociedades musulmanas se rijan por la shari’a, que consideran de origen divino.

\section{REFERENCIAS}

Abou Al-Samh, R. (2011, 13-19 de octubre). Saudi Shias riot yet again for better conditions. Al Ahram Weekley, núm. 1068. Descargado de http://weekly.ahram .org.eg/2011/1068/re9.htm. Última consulta el 23 de enero de 2012.

AbuKhalil, A. (2012, 5 de enero). The ugly face of the Muslim Brotherhood. Al Akhbar English. Descargado de http://english.al-akhbar.com/blogs/angrycorner/ugly-face-muslim-brotherhood. Última consulta el 8 de enero de 2012.

Achcar, G. (2012, 29 de enero). Theses on the "Arab Spring". Jadaliyya ezine. Descargado de http://www.jadaliyya.com/pages/index/4184/theses-on-the-arabspring. Última consulta el 23 de julio de 2012.

Arteaga Pérez, J. and V. Brachet-Márquez (2011). Dominación y contienda: seis estudios de pugnas y transformaciones (1910-2010). México: El Colegio de México, Centro de Estudios Sociológicos.

Bayat, A. (2007). Making Islam democratic: social movements and the post-Islamist turn. Stanford: Stanford University Press.

Bayat, A. (2010) Life as politics: how ordinary people change the Middle East. Stanford: Stanford University Press.

Beblawi, H. (1990). The rentier state in the Arab world. In G. Luciani (Ed.), The Arab state, pp. 85-98. Los Angeles: University of California Press.

Brachet-Márquez, V. (1996). El pacto de dominación: estado, clase y reforma social en México, 1910-1995. México, D.F.: El Colegio de México, Centro de Estudios Sociológicos.

Corm, G. (1999). Le Proche-Orient éclaté : 1956-2000. Gallimard. (Folio/Histoire).

Democracia Real Ya! (2011, mayo). Manifiesto “Democracia real ya!" Descargado de http://www.democraciarealya.es/manifiesto-comun/. Última consulta el 10 de enero de 2012.

Esposito, J. and J. Voll. (1996). Islam and Democracy. Nueva York: Oxford University Press.

Hamdan, S. (2011, 14 de septiembre). Qatar shows faith in Europe. The New York Times. Descargado de http://www.nytimes.com/2011/09/15/world/middleast/ qatar-shows-faith-in-europe.html? $\backslash \mathrm{s} \backslash \mathrm{do5}(\mathrm{r})=3$. Última consulta el 23 de enero de 2012.

Held, D. (2006). Models of democracy (3rd ed.). Cambridge, UK: Polity.

Hertog, S. (2011, 31 de mayo). The costs of counter-revolution in the GCC. Foreign Policy Magazine. Descargado de http://mideast.foreignpolicy.com/posts/ 2011/05/31/the_costs_of_counter_revolution_in_the_gcc. Última consulta el 2 de noviembre de 2011. 
Huntington, S.P. (1998). The clash of civilizations and the remaking of world order. Nueva York: Simon \& Schuster.

Ibrahim, S. (2011, 17 de diciembre). Ikhwan wa "qatariyun".. wa salafiyun wa "sa'udiyun". Al-Masry Al-Youm. Descargado de http://www.almasryalyoum .com/node/553556. Última consulta el 8 de enero de 2012.

Kolko, G. (2006). The age of war: The United States confronts the world. Boulder y Londres: Lynne Rienner.

Lewis B. (1990, September). The roots of muslim rage. The Atlantic Magazine. 266 (60):47-54. Descargado de http://www.theatlantic.com/magazine/archive/ 1990/09/the-roots-of-muslim-rage/304643/. Última consulta el 3 de agosto de 2012.

Luciani, G. (1990). Allocation vs. production states: A theoretical framework. In G. Luciani (Ed.) The Arab state, pp. 65-84. Los Angeles: University of California Press.

MacFarquhar, N. (2011, 27 de mayo). Saudi Arabia scrambles to limit region's upheaval. The New York Times. Descargado de http://www.nytimes.com/ 2011/05/28/world/middleeast/28saudi.html? \s \do5(r)=1. Última consulta el 2 de noviembre de 2011.

Mulligan, C. B. (2011, 23 de marzo). How oil wealth undercuts democracy in Libya. Economix: New York Times Economics Blogs. Descargado de http://economix .blogs.nytimes.com/2011/03/23/how-oil-wealth-undercuts-democracy/. Última consulta el 30 de agosto de 2011.

Obama, B. H. (2011, 19 de mayo). Remarks by the President on the Middle East and North Africa. The White House - Office of the Press Secretary. Descargado de http://www.whitehouse.gov/the-press-office/2011/05/19/remarks-presidentmiddle-east-and-north-africa. Última consulta el 9 de enero de 2012.

Occupy Wall Street (2012, enero). Occupy Wall Street day 129. Descargado de http://www.adbusters.org/campaigns/occupywallstreet. Última consulta el 23 de enero de 2012.

Scott, M. (2011, 11 de octubre). Qatar bets on hobbled European banks. Deal Book, The New York Times blog. Descargado de http://dealbook.nytimes.com/ 2011/10/11/qatar-bets-on-hobbled-european-banks/. Última consulta el 23 de enero de 2012.

Said, E.W. (2001, 22 de octubre). The clash of ignorance. The Nation 22(10). Descargado de http://www.thenation.com/article/clash-ignorance. Última consulta el 3 de julio de 2012.

Smith, H. (2011, 16 de diciembre). Greeks fearing collapse of eurozone bailout pulled record sums from bank. The Guardian. Descargado de http://www .guardian.co.uk/business/2011/dec/16/greeks-fearing-collapse-of-eurozonebailout-pulled-record-sums-from-bank. Última consulta el 7 de enero de 2012.

Van Den Boogaerde, P. (1991). Financial assistance from Arab countries and Arab regional institutions. Occasional Paper - International Monetary Fund. Washington, D.C.: International Monetary Fund. 